\title{
Factors associated with stunting among children below five years of age in Zambia: evidence from the 2014 Zambia demographic and health survey
}

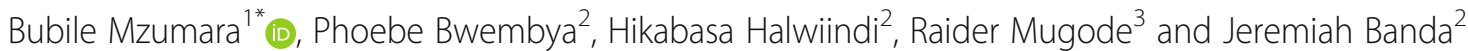

\begin{abstract}
Background: Stunting continues to be a major public health problem globally. Stunting is a manifestation of many factors including inadequate food intake and poor health conditions. However, poor quality nutritional diets during pregnancy, infancy and early childhood lead to inadequate nutrient intake. The prevalence of stunting in Zambia has been over $40 \%$ and remains unacceptably high. There is limited information on factors associated with stunting in Zambia. Thus to better understand factors contributing to the high stunting levels, the 2013/14 Zambia Demographic and Health Survey (ZDHS) data was analysed.
\end{abstract}

Methods: Data was extracted using a data extraction tool and analysed using Stata version 13. Sample data of 12, 328 children aged 0-59 months was analysed. The analysis involved simple and multiple logistic regression to find associations between independent variables and stunting.

Results: The prevalence of stunting among under five children in Zambia is 40\%. From the 4937 children who were stunted, stunting was higher among male children as compared to female children ( 42.4 and $37.6 \%$ respectively). Additional analysis revealed that children whose source of drinking water was improved (33.7\%) were less likely to be stunted compared to children whose source of drinking water was poor (47.7\%). Stunting was associated with sex and age of a child; mother's age and education; residence; wealth and duration of breastfeeding. For instance, children whose mothers had higher education showed a $75 \%$ reduction of odds compared to children whose mothers had no education ( $\mathrm{AOR}=0.35,95 \% \mathrm{Cl}: 0.22,0.54 ; p<0.05$ ). Similarly, wealth status showed an inverse relationship. Children who came from rich households showed a $32 \%$ reduction of odds compared to children who came from poor households ( $\mathrm{AOR}=0.68,95 \% \mathrm{Cl}: 0.57,0.82 ; p<0.05$ ).

Conclusion: The study established that the major predictors of stunting among children under 5 years old in Zambia were sex and age of the child; mother's age and level of education; wealth status; improved source of drinking water; duration of breastfeeding and residence. Therefore, multiple measures targeted at reducing child stunting should be taken in a bid to influence policy and conceiving of programmes.

Keywords: Stunting, Zambia demographic and health survey, Socio-demographic factors, Children

\footnotetext{
*Correspondence: bubilemzumara@yahoo.com

${ }^{1}$ University of Zambia School of Public Health, Nationalist Road, U. T. H, P.O.

Box 50110, Lusaka, Zambia

Full list of author information is available at the end of the article
}

(c) The Author(s). 2018 Open Access This article is distributed under the terms of the Creative Commons Attribution 4.0 International License (http://creativecommons.org/licenses/by/4.0/), which permits unrestricted use, distribution, and reproduction in any medium, provided you give appropriate credit to the original author(s) and the source, provide a link to the Creative Commons license, and indicate if changes were made. The Creative Commons Public Domain Dedication waiver (http://creativecommons.org/publicdomain/zero/1.0/) applies to the data made available in this article, unless otherwise stated. 


\section{Background}

Stunting continues to be a major public health problem globally. A child is 'stunted' if his or her height is less than negative two standard deviations below the World Health Organization standard [1]. Globally, about 161 million children under the age of 5 years are stunted while 51 million children do not weigh enough for their height (wasted), and are not in healthy state [2]. Over the years, the prevalence of stunting has reduced but overall progress is insufficient and many children are still at risk. The prevalence of stunting is highest in developing countries, that is, in Asia and Africa where stunting is more prevalent than underweight or wasting. According to UNICEF [3], 40\% of children in Eastern and Southern Africa, under 5 years of age are stunted. Stunting has not spared Zambia. According to the recent Zambia Demographic and Health Survey (ZDHS), about $40 \%$ of children under-age five are stunted with Northern Province having the highest prevalence at $49 \%$ [4].

Long-term restriction of a child's potential growth brought about by insufficient nutritious food intake coupled with poor health conditions can lead to stunting. Stunting may start as early in pregnancy, infancy and early childhood due to poor quality nutritional diets that may lead to inadequate nutrient intake. Furthermore, poor socio-economic conditions and increased risk of frequent exposure to certain conditions, such as illness or inappropriate feeding practices may give rise to high levels of stunting [5]. Adequate intake of nutrients is, therefore, essential for growth and mental development and long-term good health.

Consequences of stunting include short adult height, effect on health and negative impact on economic development over time [6]. Stunting has long-term effects on individuals and societies; including diminished cognitive and physical development reduced productive capacity and poor health, and an increased risk of degenerative diseases such as diabetes [3]. For instance, short adult height among women has an impact on the health and survival of their children while for men it may even result in low economic productivity. The government of the Republic of Zambia has put in place measures to address the high levels of stunting through child nutrition programmes and Policies such as the National Food and Nutrition Strategic Plan. Some nutrition programmes include infant and young child feeding, management of acute malnutrition, micronutrient deficiency control and hygiene, water and sanitation. However, despite the spelled out commitments and programmes, stunting still remains considerably high among children aged under 5 years in Zambia compared to WHO standards.

In Zambia, information concerning factors associated with stunting has been very scanty and limited. There is, therefore, need to adequately shed more light on why Zambia continues to experience high levels of stunting.
The resulting findings would inform policy and programmes. Stunting has a number of implications on children, which later manifests into adulthood and negatively impact the nation as a whole. Thus, the purpose of this study was to identify socio-economic factors that were associated with stunting among children aged 0 to 59 months in Zambia.

\section{Methods}

\section{Study setting}

Zambia is a landlocked country located in Sub-Sahara African. It has 10 provinces namely Central, Copperbelt, Eastern, Luapula, Lusaka, Muchinga, Northern, North-Western, Southern and Western. These provinces are further sub-divided into districts, constituencies and wards. Economically the country mostly depends on Copper and Cobalt exports. The majority of the population lives in the rural areas and are highly dependent on agriculture for their livelihood. Zambia like most developing countries has a young population with $45.4 \%$ of persons aged below 15 years with a life expectancy at birth estimated at 51.2 years ( 51.7 years in rural areas and 50.8 years in urban areas) [4].

\section{Data sources}

The study extracted data for children less than 5 years of age from the 2013/2014 Zambia Demographic Health Survey database.. The ZDHS was a cross-sectional survey which gathered information on levels and trends in fertility, childhood mortality, use of family planning methods, and maternal and child health indicators including HIV and AIDS [4]. The survey was a nationally representative probability sample of women in the reproductive age 15 to 49 and men 15 to 59 years. The ZDHS provides information on levels and trends in fertility, childhood mortality, use of family planning methods, and maternal and child health indicators including HIV and AIDS at national level for both rural and urban areas of the country [4].

\section{Sampling and data collection methods}

The ZDHS adopted frame of primary sampling units of the 2010 Zambian Census of Population and Housing. The sampling frame consisted of 25,631 Enumeration areas (EAs) and 2,815,897 households. The 2013 /2014, ZDHS adopted a two-stage stratified-cluster sample design where enumeration areas (EAs) where the first stage units and households were selected during the second stage units. The study only included data on children aged zero to 59 months of age with age and height measurements. An enumeration area is a convenient geographical area with an average size of 130 households or 600 people. The sample consisted of 722 Standard enumeration areas (SEAs) from which a selection of 18,050 households was made. The survey interviewed all women aged 15-49 and men 
aged 15-59 who were either permanent residents of the households or visitors present in the households on the night before the survey. The ZDHS collected data using three questionnaires, namely, the Household Questionnaire, the Woman's Questionnaire, and the Man's Questionnaire. The survey interviewed 16,411 women aged 15-49 and 1, 4773 men age 15-59. Children aged 0-59 months and women aged 15-49 who were usual residents of or visitors in the household had their height and weight measured to assess nutritional status. The survey captured 13,554 children under-five, however only 12, 328 children had their height and weight measurements taken.

\section{Statistical analysis}

The main objective of the study was to identify factors that were associated with stunting in Zambia. The study adopted the United Nations Children's Fund (UNICEF) conceptual framework of the determinants of the nutritional status as it represented a comprehensive aspects of how undernutrition is the outcome of specific development problems related directly to the dietary intake and the health status of an individual. The ZDHS dataset was de-identified to prevent a person's identity from being linked with information. Firstly, a binary variable was created to define stunting that is "stunted" (Z-score equal to and less than - $2 \mathrm{SD}$ ) and "not stunted" (Z-score greater than - 2 SD). Based on literature and guidance from the conceptual framework the study included the following independent variables: sex of child, age of the child, mother's Education, age of Mother, number of children under-five in the household, duration of breastfeeding, residence (Urban/Rural), place of delivery, type of delivery assistance, wealth status, and quality of source of drinking water. In addition, a variable was created and categorized as either being improved (piped water, protected well and spring, bottled water and rainwater) and non-improved (unprotected well and spring, tanker, surface water and other). With regards to wealth index used in the ZDHS it was a measure that has been used in many DHS and other country-level surveys to indicate inequalities in household characteristics, use of health care and other services, and health outcomes [4]. The indicator serves as a level of wealth that is consistent with expenditure and income measures. It is constructed using household asset data following a principal components analysis [ibid].

Statistical analysis was performed using Stata version 13 (StataCorp, College Station, Texas, USA). The datasets for women and households were used and applied sample weights to adjust for nonresponse. The data assumed normal distribution, as the sample size was relatively big and representative of the population. The main analysis involved descriptive statistics such as proportions to summarise characteristics of participants. Pearson's Chi-Square test was used to explore relationships between prevalence of stunting and the independent variables. Reported $p$-values $<0.05$ and $95 \%$ standard normal level were considered statistically significant that is suggesting strong evidence of an association between stunting and an independent variable. In addition, simple and multiple logistic regression was done to measure the net associations of all variables and stunting. Results were reported for each factor and prevalence of stunting after which predictors with significant $p$-values (that is $p<0.05$ and $95 \%$ confidence interval) were considered for multiple logistic analysis. In the multiple regression, the final model was generated using a researcher led backward stepwise regression. Variables were entered in the model and associations were considered statistically significant when $p<0.05$. The Odds ratios determined the odds of being stunted or not.

\section{Ethical consideration}

Institutional authorization was obtained from the University of Zambia Biomedical Research Ethics Committee (UNZABREC) to conduct the research (Reference number 009-06-16). The Central Statistical Office (CSO) granted permission to use the 2013/14 ZDHS dataset for the study. The researcher ensured unauthorized access, accidental loss or destruction of the dataset by encrypting the dataset on a computer accessible using a password.

\section{Results}

The study included 12,328 children aged $0-59$ months who had their height and age measured. The results showed that $4937(40 \%)$ children under 5 years of age were stunted. Northern Province had the highest prevalence of stunting while Lusaka province had the lowest. Figure 1 below shows prevalence of stunting across the country by province.

Prevalence of stunting was higher among male children compared to female children at 42 and 38\% respectively. Lowest prevalence rates of stunting included the following attributes: children whose mothers had higher education, children in urban areas, children from a rich status, children exposed to improved source of drinking water, delivered from private mission hospital, mothers received delivery assistance from a health professional, one or two under five children in the $\mathrm{H} / \mathrm{H}$, children aged below 6 months. See Table 1 below presents the descriptive statistics of stunting and independent variables.

Results from the simple and multiple logistic regression analysis are presented in Tables 2 and 3. The adjusted odds ratio shows that sex of a child, age of a child, residence, mothers' level of education, wealth status, mothers' age, duration of breastfeeding and improved source of drinking water were among the factors associated with stunting in children. The associations between stunting and the variables were considered to be statistically 


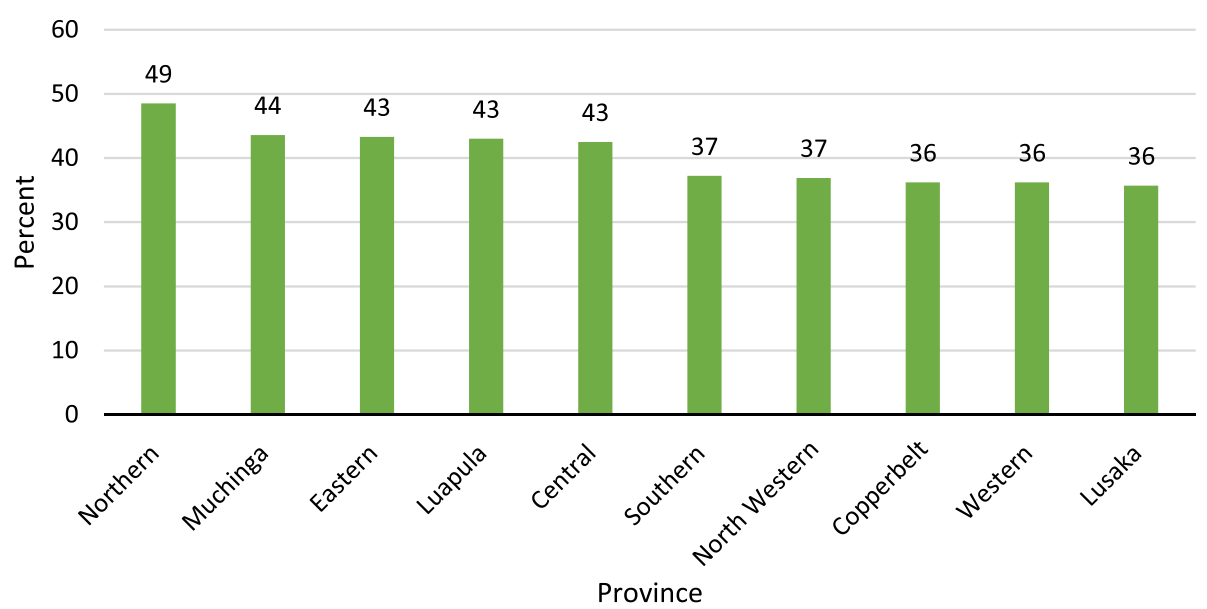

Fig. 1 Percentage distribution of Stunting by province

significant when $p<0.05$. Table 2 below shows results from the simple and multiple logistic regression.

Table 3 summarizes the results of the backward stepwise logistic regression models, which measured the net associations of all the independent variables with stunting. For characteristics that remained significant in the model, the odds ratios did not change substantially from the bivariate analysis. Child's sex was significant for predicting stunting. Children in rural areas were $19 \%$ less likely to be stunted compared with children living in urban areas $(\mathrm{AOR}=0.81$, 95\%CI: $0.70,0.95 ; p<0.05$ ), While children aged 24 to 35 months of age had 7 times higher odds of being stunted compared with children less than 6 months. The analysis showed that, child's sex, child age, mothers' age and level of education, residence, improved source of drinking water and duration of breastfeeding were significant for predicting stunting.

\section{Discussion}

Early childhood development is crucial especially the first 1000 days of an infant's life after which stunting is irreversible. Long-term effects of stunting include diminished cognitive and physical development, poor health and adult short stature. The study intended to identify the factors associated with stunting among children aged 0 to 59 months using latest ZDHS data. The prevalence of stunting among children under five was $40 \%$ and was more prevalent among male children than female children. This finding is similar to other studies conducted around the world that have also documented higher prevalence of stunting in boys than in girls [7-9]. According to Chirande et al. [5] sex differences could also be attributed to behavioural patterns of communities for instance, favouritism towards daughters. Additionally, epidemiological evidence depicts boys to be biologically more vulnerable to morbidity $[10,11]$.
Over the years studies have observed that populations that live in rural areas have been more susceptible to nutritional deficits due to a number of disadvantages however, according to the results of the present study, children in urban areas had a higher risk for stunting than children in rural areas. Our study agrees with other studies that found similar results $[12,13]$. This risk of stunting in urban areas might be due to decreased maternal contact time due to work schedules of working mothers that may bring about short period of breastfeeding, early cessation of breastfeeding and improper complementary food, which have a largely negative effect on the growth of the children. This entails that most of the urban population might actually be urban poor who live in informal settlements/unauthorised slums in abject poverty, poor water and sanitation, high food insecurity and limited nutritious foods. Rural populations may have opportunities to grow nutritious rich foods while urban poor are highly dependent on food purchase and diets lack diversity. On the contrary, our study contradicts other studies that have revealed no significant association between urban or rural location [14, 15]. There is, therefore, need of establishing strategies that facilitate proper nutrition and child health in urban areas especially among the poor.

Mother's education continues to be associated with stunting. Higher odds of stunting being observed among children whose mothers had no education. The same has been confirmed in previous studies and the results imply that maternal education may provide protective effects against all under-nutrition indicators in children $[5,14,16,17]$. Mothers who are more educated are more likely to be more conscious about their children's health. Moreover, due to exposure to media they are likely to have better child and healthcare knowledge of nutrition leading to better feeding practices. However, other studies show contrary results in that there was no significant 
Table 1 Prevalence of stunting in children under five by characteristics of children $(n=4937)$

\begin{tabular}{|c|c|c|c|c|c|c|c|}
\hline Characteristics & $\begin{array}{l}\text { Children with } \\
\text { stunting }\end{array}$ & $\begin{array}{l}\text { Children without } \\
\text { stunting }\end{array}$ & $p$-value & Characteristics & $\begin{array}{l}\text { Children with } \\
\text { stunting }\end{array}$ & $\begin{array}{l}\text { Children without } \\
\text { stunting }\end{array}$ & $p$-value \\
\hline Sex of Child & & & & Never Breast fed & $1777(43.3)$ & $2324(56.7)$ & \\
\hline Male & $2626(42.4)$ & $3562(57.6)$ & $<0.001$ & Still Breastfeeding & 1415 (35.0) & $2622(65.0)$ & \\
\hline Female & $2311(37.6)$ & $3828(62.4)$ & & U5 children in $\mathrm{H} / \mathrm{H}$ & & & \\
\hline Age of Mother (years) & & & & 1 or 2 & $3794(39.8)$ & $5741(60.2)$ & 0.3937 \\
\hline $15-19$ & $343(43.9)$ & $438(56.1)$ & 0.146 & $3-5$ & $1060(40.6)$ & $1550(59.4)$ & \\
\hline $20-24$ & $1200(41.8)$ & $1531(58.2)$ & & $6+$ & $33(53.3)$ & $29(46.7)$ & \\
\hline $25-29$ & $1154(39.4)$ & $1777(60.6)$ & & Child's age (months) & & & \\
\hline $30-34$ & $944(39.4)$ & $1453(60.6)$ & & $<6$ & 141(13.6) & $891(86.4)$ & $<0.001$ \\
\hline $35-39$ & $601(37.9)$ & $984(62.1)$ & & $6-11$ & $380(31.9)$ & $811(68.1)$ & \\
\hline $40-44$ & $308(38.5)$ & $491(61.5)$ & & $13-23$ & $1212(48.4)$ & $1294(51.6)$ & \\
\hline $45-49$ & $65(35.1)$ & $119(64.9)$ & & $24-35$ & $1249(51)$ & $1201(49)$ & \\
\hline Mother's Level of Education & & & & $36-47$ & 1038(41.6) & $1459(58.4)$ & \\
\hline No Education & $585(44.1)$ & $725(55.4)$ & $<0.001$ & $48-59$ & 919 (34.6) & $1734(65.4)$ & \\
\hline
\end{tabular}

Primary (grade 1-7)

Secondary (grade 8-12)

Higher (college or university)

$2738(42.0) \quad 3780(58.0)$

$1230(36.9) \quad 2104(63.1)$

$74(18.1) \quad 333(81.9)$

Residence

Urban

$1491(36.0) \quad 2649(64.0)$

$<0.001$

Rural

$3447(42.1)$

$4741(57.9)$

Wealth Status

Poor

Middle

2566 (44.6) $3192(55.4)$

$<0.001$

$1047(40.2)$

$1557(59.8)$

Rich

$1325(33.4)$

2641 (66.6)

Source of Drinking Water

Improved

2459 (37)

$4125(63)$

$<0.001$

Non-improved

1958 (44)

2519 (56)

Place of Delivery

\section{Home}

Government/public sector

Private mission Hospital

Other

1572 (44.1)

1996 (55.9)

$<0.001$

2687 (38)

4391 (62.0)

196 (36.8)

$336(63.2)$

49 (44.0)

$603(56.0)$

Type of delivery assistance

Health Professional

$2726(37.7)$

TBA

$842(44.1)$

4507 (62.3)

$<0.001$

Relative or Other

$762(43.5)$

$(55.9)$

No One

$170(45.1)$

$989(56.5)$

Duration of Breastfeeding (months)

$\begin{array}{lll}0-6 & 78(47.1) & 87(52.9) \\ 7-12 & 212(40.2) & 315(59.8) \\ 13-18 & 955(40.9) & 1381(59.1) \\ 19-47 & 1711(43.3) & 2242(56.7)\end{array}$

Table 1 Prevalence of stunting in children under five by characteristics of children $(n=4937)$ (Continued)

association between stunting and maternal education $[18,19]$. While most studies have shown that maternal education is a determinant of a child's nutritional status, other studies have actually indicated that father's education is equally an important factor for child nutrition [20, 21]. Therefore, the importance of maternal education might vary from country to country and the difference may be probably due to differences in study design and as well as different socio-economic statuses of countries.

In relation to mother's age, the differences in prevalence of stunting decreased with maternal age. Lower odds of stunted were observed among children whose mothers were aged above 35 years old. The study results corroborate with other studies $[5,22]$. This may be because young mothers require adequate nutrition for them to grow into adults and as a young mother; food shared in small proportion between the infant and the mother is not adequate. In addition, younger mothers may tend to have poor knowledge and practices of good nutrition for young children.

Water and sanitation also has a significant impact on child nutritional status as lack of water in households makes basic hygiene somewhat unattainable. In the present study, stunting was significantly associated with improved source of drinking water. Children whose source of drinking water was non-improved were likely to be stunted compared to children whose source of water was improved. This may be attributed to the fact that non-improved water sources may be contaminated and thus may increase risk of infection such as diarrhoea. The study findings are consistent with other studies [23-26]. However, the study findings are also contrary to previous studies $[16,18,27,28]$, that depict no significant association between source of drinking water and stunting. 
Table 2 Crude and adjusted measures of the effect of independent variables on stunting in children aged 0-59 months

\begin{tabular}{|c|c|c|}
\hline Characteristics & $\begin{array}{l}\text { Crude OR } \\
(95 \% \mathrm{Cl})\end{array}$ & $\begin{array}{l}\text { Adjusted OR } \\
(95 \% \mathrm{Cl})\end{array}$ \\
\hline \multicolumn{3}{|l|}{ Sex of Child } \\
\hline Male & 1 & 1 \\
\hline Female & $0.85(0.78-0.92)^{*}$ & $0.80(0.73,0.88)^{*}$ \\
\hline \multicolumn{3}{|l|}{ Age of Mother (years) } \\
\hline $15-19$ & 1 & 1 \\
\hline $20-24$ & $0.95(0.79-1.12)$ & $0.83(0.69-1.00)$ \\
\hline $25-29$ & $0.85(0.71-1.02)$ & $0.73(0.60-0.89)$ \\
\hline $30-34$ & $0.86(0.72-1.04)$ & $0.73(0.60-0.89)$ \\
\hline $35-39$ & $0.80(0.66-0.98)^{*}$ & $0.64(0.52-0.80)^{*}$ \\
\hline $40-44$ & $0.85(0.68-1.05)$ & $0.65(0.51-0.83)^{*}$ \\
\hline $45-49$ & $0.74(0.50-1.09)$ & $0.60(0.40-91)$ \\
\hline \multicolumn{3}{|l|}{ Mother's Level of Education } \\
\hline No Education ( & 1 & 1 \\
\hline Primary (grade 1-7) & $0.93(0.8-1.08)$ & 0.93(0.79-1.10) \\
\hline Secondary (grade 8-12) & $0.74(0.63-0.87)^{*}$ & $0.84(0.70-1.02)$ \\
\hline Higher (college and university) & $0.26(0.18-0.38)^{*}$ & $0.35(0.23-0.55)^{*}$ \\
\hline \multicolumn{3}{|l|}{ Residence } \\
\hline Urban & 1 & 1 \\
\hline Rural & $1.32(1.18-1.47)^{*}$ & $0.78(0.68-0.92)^{*}$ \\
\hline \multicolumn{3}{|l|}{ Wealth Index } \\
\hline Poor & 1 & 1 \\
\hline Middle & $0.84(0.75-0.95)^{*}$ & $0.84(0.74-0.96)$ \\
\hline Rich & $0.61(0.54-0.69)^{*}$ & $0.69(0.57-0.82)^{*}$ \\
\hline \multicolumn{3}{|l|}{ Source of Drinking Water } \\
\hline Improved & 1 & \\
\hline Non-improved & $1.31(1.19-1.44)^{*}$ & $1.13(1.02-1.26)$ \\
\hline \multicolumn{3}{|l|}{ Place of Delivery } \\
\hline Home & 1 & 1 \\
\hline Gov public sector & $0.77(0.7-0.85)^{*}$ & $0.88(0.68-1.15)$ \\
\hline Private mission Hospital & $0.71(0.57-0.88)$ & $0.84(0.60-1.17)$ \\
\hline Other & $0.96(0.63-1.47)$ & $0.94(0.60-1.48)$ \\
\hline \multicolumn{3}{|l|}{ Type of delivery assistance } \\
\hline Health Professional & 1 & 1 \\
\hline TBA & $1.31(1.16-1.48)^{*}$ & $0.98(0.77-1.25)$ \\
\hline Relative or Other & $1.29(1.14-1.46)^{*}$ & $0.98(0.74-1.32)$ \\
\hline No One & $1.30(1.03-1.65)$ & $1.04(0.72-1.51)$ \\
\hline \multicolumn{3}{|l|}{ Duration of Breastfeeding (months) } \\
\hline $0-6$ & 1 & 1 \\
\hline $7-12$ & $0.75(0.51-1.12)$ & $0.67(0.44-1.01)$ \\
\hline $13-18$ & $0.77(0.52-1.12)$ & $0.65(0.44-0.96)$ \\
\hline $19-47$ & $0.86(0.59-1.28)$ & $0.69(0.46-1.04)$ \\
\hline Never Breast fed & $0.86(0.59-1.28)$ & $0.97(0.55-1.70)$ \\
\hline Still breastfeeding & $0.60(0.41-0.89)$ & $0.65(0.42-1.00)$ \\
\hline
\end{tabular}

Table 2 Crude and adjusted measures of the effect of independent variables on stunting in children aged 0-59 months (Continued)

\begin{tabular}{lll}
\hline Characteristics & $\begin{array}{l}\text { Crude OR } \\
(95 \% \mathrm{Cl})\end{array}$ & $\begin{array}{l}\text { Adjusted OR } \\
(95 \% \mathrm{Cl})\end{array}$ \\
\hline $\begin{array}{l}\text { U5 children in } \mathrm{H} / \mathrm{H} \\
1 \text { or } 2\end{array}$ & 1 & 1 \\
$3-5$ & $1.04(0.94-1.17)$ & $1.1(0.96-1.22)$ \\
$6+$ & $1.45(0.67-3.13)$ & $1.71(0.79-3.71)$ \\
Child age (months) & & \\
$<6$ & 1 & 1 \\
$6-11$ & $2.22(1.63-3.01)^{*}$ & $3.22(2.44-4.25)^{*}$ \\
$13-23$ & $4.31(3.2-5.8)^{*}$ & $4.52(5.03-8.84)^{*}$ \\
$24-35$ & $5.16(4.04-6.61 *)$ & $5.88(5.26-9.75)^{*}$ \\
$36-47$ & $7.84(6.09-10.1)^{*}$ & $8.97(3.76-7.20)^{*}$ \\
$48-59$ & $6.85(5.42-8.65)^{*}$ & $8.3(2.76-5.18)^{*}$ \\
\hline
\end{tabular}

In relation to number of children in the household, smaller families are generally socio-economically advantaged accompanied by improved quality of life. In the present study, although the highest OR for stunting correspond to children belonging to families with six or more children the same was not confirmed in the multiple analysis after adjustment by other factors. These results are contrary to other studies $[9,22,29,30]$, which observed a significant relationship between stunting and number of under five children in a household.

Type of delivery assistance and place of delivery showed significant statistical relations in the bivariate analysis, however, with respect to multiple logistic regression analysis they did not show statistical significance. In this study type of delivery assistance and place of delivery were, therefore, statistically insignificant factors with regard to the association with stunting.

The present study had a number of limitations. Firstly, an in-built limitation of cross-sectional data is their snapshot nature that makes establishing a temporal sequence of events and drawing causal inferences difficult as this pertains to the period and season the survey was undertaken. A few key variables could not be included because of difference in classifications, as data was collected and classified by ZDHS team. For instance, the ZDHS only classifies urban residence as urban even though it includes peri-urban areas thus the definition was not precise. Although the study excluded other key variables from the analysis, our model did reflect all those variables linked to childhood stunting. The ZDHS often has a delay in publishing results, which implies that information might not be a true reflection of the current situation.

\section{Conclusions}

Stunting is associated with factors including nutrition, socio-economic, demographic and environmental factors 
Table 3 Predictors of Stunting using Backward Step Multiple Regression

\begin{tabular}{|c|c|c|}
\hline Characteristics & $\begin{array}{l}\text { Adjusted Odds } \\
\text { Ratio }(95 \% \mathrm{Cl})\end{array}$ & $\begin{array}{l}\text { Adjusted } \\
P \text {-value }\end{array}$ \\
\hline \multicolumn{3}{|l|}{ Sex of Child } \\
\hline Male & 1 & \\
\hline Female & $0.80(0.73-0.88)$ & $<0.001$ \\
\hline \multicolumn{3}{|l|}{ Age of Mother (years) } \\
\hline $15-19$ & 1 & \\
\hline $20-24$ & $0.83(0.69-1.00)$ & 0.046 \\
\hline $25-29$ & $0.74(0.60-0.90)$ & 0.002 \\
\hline $30-34$ & $0.73(0.60-0.89)$ & 0.002 \\
\hline $35-39$ & $0.65(0.52-0.81)$ & $<0.001$ \\
\hline $40-44$ & $0.65(0.51-0.83)$ & $<0.001$ \\
\hline $45-49$ & $0.61(0.41-0.92)$ & 0.018 \\
\hline \multicolumn{3}{|l|}{ Mother's Level of Education } \\
\hline No Education & 1 & \\
\hline Primary (grade 1-7) & $0.93(0.79-1.10)$ & 0.411 \\
\hline Secondary (grade 8-12) & $0.83(0.69-1.00)$ & 0.055 \\
\hline Higher (college and university) & $0.35(0.22-0.54)$ & $<0.001$ \\
\hline \multicolumn{3}{|l|}{ Residence } \\
\hline Urban & 1 & \\
\hline Rural & $0.81(0.70-0.95)$ & 0.009 \\
\hline \multicolumn{3}{|l|}{ Wealth Index } \\
\hline Poor & 1 & \\
\hline Middle & $0.85(0.74-0.97)$ & 0.013 \\
\hline Rich & $0.68(0.57-0.82)$ & $<0.001$ \\
\hline \multicolumn{3}{|l|}{ Source of Drinking Water } \\
\hline Improved & 1 & \\
\hline Non-improved & $1.13(1.03-1.27)$ & 0.016 \\
\hline \multicolumn{3}{|l|}{ Duration of Breastfeeding (months) } \\
\hline $0-6$ & 1 & \\
\hline $7-12$ & $0.66(0.44-1.01)$ & 0.054 \\
\hline $13-18$ & $0.65(0.44-0.97)$ & 0.034 \\
\hline $19-47$ & $0.69(0.46-1.04)$ & 0.075 \\
\hline Never BF & $0.96(0.54-1.69)$ & 0.883 \\
\hline still BF & $0.65(0.42-0.99)$ & 0.045 \\
\hline \multicolumn{3}{|l|}{ Child age (months) } \\
\hline$<6$ & 1 & \\
\hline $6-11$ & $3.23(2.46-4.26)$ & $<0.001$ \\
\hline $13-23$ & $6.77(5.24-8.75)$ & $<0.001$ \\
\hline $24-35$ & $7.08(5.2-9.65)$ & $<0.001$ \\
\hline $36-47$ & $5.18(3.74-7.16)$ & $<0.001$ \\
\hline $48-59$ & $3.76(2.74-5.16)$ & $<0.001$ \\
\hline
\end{tabular}

that impact on children's health and wellbeing. These factors often not only influence stunting but also influence nutritional status of a child. Therefore, improvements in maternal education, household wealth, diet diversity, water and sanitation could improve health status of children. Stunting affects health status and productivity later in adult life. Thus, the consequences of socio-economic inequalities in childhood nutritional status are likely to be recurring. Therefore, with this information on factors associated with stunting, there is need to address all causes of stunting in an integrated manner. Policies and programmes should also give greater attention to improving maternal education especially among younger mothers, improve social-economic status and improve water sources, sanitation and hygienic practices.

\section{Abbreviations}

CSO: Central statistics office; HAZ: Height-for-Age Z-score; SUN: Scaling up Nutrition; UN: United Nations; UNICEF: United Nation International Children Fund; UNZA: University of Zambia; WHO: World Health Organization;

ZDHS: Zambia Demographic Health Survey

\section{Acknowledgements}

I would like to express my heartfelt gratitude to my Heavenly Father Jesus who helped me to accomplish this thing successfully. Also to my advisors Dr. P. Bwembya, Ms. R Mugode, Dr. H. Halwiindi and Dr. Jeremiah Banda who have been giving me a great help to the completion of this research dissertation starting from commenting the draft of my proposal and giving very important suggestions. I would also like to extend my appreciation to those who have helped me a lot in giving additional advice.

\section{Funding}

No funding was obtained for this study.

\section{Availability of data and materials}

The data that support the findings of this study are available from Central Statistics Office Zambia but restrictions apply to the availability of these data, which were used under permission for the current study, and so are not publicly available. Data are however available from the authors upon reasonable request and with permission of Central Statistics Office Zambia.

\section{Authors' contributions}

BM performed the statistical analysis and drafted the manuscript. PB, $\mathrm{HH}$ and RM participated in the design of the study, data analysis and revising of the thesis and manuscript. JB participated in the statistical analysis and review of the methods section. All authors read and approved the final manuscript.

\section{Ethics approval and consent to participate}

Institutional authorization was obtained from the University of Zambia Biomedical Research Ethics Committee (UNZABREC) to conduct the research (Reference number 009-06-16). CSO granted permission to use the 2013/14 ZDHS dataset for the study. The researcher ensured unauthorized access, accidental loss or destruction of the dataset by encrypting the dataset on a computer accessible using a password.

\section{Consent for publication}

Not applicable.

\section{Competing interests}

The authors declare that they have no competing interests.

\section{Publisher's Note}

Springer Nature remains neutral with regard to jurisdictional claims in published maps and institutional affiliations. 


\section{Author details}

${ }^{1}$ University of Zambia School of Public Health, Nationalist Road, U. T. H, P.O. Box 50110, Lusaka, Zambia. 'University of Zambia, School of Public Health, Nationalist Road, U .T. H, P.O. Box 50110, Lusaka, Zambia. ${ }^{3}$ National Food and Nutrition Commission, Plot\#5112 Lumumba Road, P. O Box 32669, Lusaka, Zambia.

Received: 15 January 2018 Accepted: 5 December 2018

Published online: 20 December 2018

\section{References}

1. WHO child growth standards. Length/height-for-age, weight-for-age, weight- for-length, weight-for-height and body mass index-for-age: methods and development. Geneva: World Health Organization; 2006.

2. United Nations Children's Fund, World Health Organization. The World Bank. UNICEFWHO-World Bank joint child malnutrition estimates. (UNICEF, New York; WHO, Geneva. Washington, DC: The World Bank; 2012.

3. United Nations Children's Fund, 2013 UNICEF report: Improving Child Nutrition: The achievable imperative for global progress.

4. Central Statistical Office (CSO) [Zambia], Ministry of Health $(\mathrm{MOH})$ [Zambia], and ICF International. Zambia Demographic and Health Survey 2013-14. Rockville, Maryland: Central Statistical Office, Ministry of Health, and ICF International; 2014

5. Chirande L, Charwe D, Mbwana H, Victor R, Kimboka S, Issaka Al, Agho KE. Determinants of stunting and severe stunting among under-fives in Tanzania: evidence from the 2010 cross-sectional household survey. BMC Pediatr. 2015;15(1):1-13 https://doi.org/10.1186/s12887-015-0482-9.

6. Dewey KG, Begum K. Long-term consequences of stunting in early life. Matern Child Nutr. 2011;7:5-18. https://doi.org/10.1111/j.1740-8709.2011. 00349.x http://siteresources.

7. Ramli, et al. Prevalence and risk factors for stunting and severe stunting among under-fives in North Maluku province of Indonesia. BMC Pediatr. 2009;9:64.

8. Wamani $\mathrm{H}$, et al. Boys are more stunted than girls in sub-Saharan Africa: a meta-analysis of 16 demographic and health surveys. BMC Pediatr. 2007;7:17.

9. LMG Cruz, et al. Factors Associated with Stunting among Children Aged 0 to 59 Months from the Central Region of Mozambique. Nutrients. 2017:9(5):491. https://doi.org/10.3390/nu9050491.

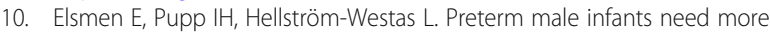
initial respiratory and circulatory support than female infants. Acta Paediatr. 2004;93:529-33 [PubMed].

11. Kilbride HW, Daily DK. Survival and subsequent outcome to five years of age for infants with birth weights less than 801 grams born from 1983 to 1989. J Perinatol. 1997(18):102-6.

12. Menon P, Ruel MT, Morris SS. Socio-economic differentials in child stunting are consistently larger in urban than in rural areas. Food Nutr Bull. 2000; 21(3):282-9.

13. Nzala SH, et al. Demographic, cultural and environmental factors associated with frequency and severity of malnutrition among Zambian children less than five years of age. J Public Health Epidemiol. 2011;3:362-70.

14. Fenske N, et al. Understanding child stunting in India: a comprehensive analysis of socio-economic, nutritional and environmental determinants using additive quantile regression. PLoS One. 2013;8(11):e78692 Available at: http://www.pubmedcentral.nih.gov/articlerender.fcgi?artid=3817074\&tool= pmcentrez\&rendertype=abstract.

15. Bwalya B, Lemba M, Mapoma C, Mutombo N. Factors associated with stunting among children aged 6-23 months in Zambian: evidence from the 2007 Zambia demographic and health survey. Int J Adv Nutr Health Sci North Am. 2015:3 Date accessed: 28 Jan. 2016.

16. Broeck K, Den V. Determinants of stunting : the role of education, information and childcare practices in Mozambique; 2007.

17. Rannan-Eliya RP, et al. Trends and determinants of childhood stunting and underweight in Sri Lanka. Ceylon Med J. 2013;58(1):10-8 Available at: http:// cmj.sljol.info/articles/10.4038/cmj.v58i1.5357/.

18. Fikadu T, Assegid S, Dube L. Factors associated with stunting among children of age 24 to 59 months in Meskan district, Gurage zone, South Ethiopia: a case-control study. BMC Public Health. 2014;14(1):800 Available at: http://www.biomedcentral.com/1471-2458/14/800.

19. Khan GN, et al. Prevalence and associated factors of malnutrition among children under-five years in Sindh, Pakistan: a cross-sectional study. BMC Nutr. 2016;2:69. https://doi.org/10.1186/s40795-016-0112-4.
20. Deshmukh PR, Sinha N, Dongre AR. Social determinants of stunting in rural area of Wardha, Central India. Med J Armed Forces India. 2013;69(3):213-7.

21. Mostafa Kamal SM. Socio-economic determinants of severe and moderate stunting among under-five children of rural Bangladesh. Malays J Nutr. 2011;17(1):105-18.

22. Darteh EKM, Acquah E, Kumi-Kyereme A. Correlates of stunting among children in Ghana. BMC Public Health. 2014;14(1):504 Available at: http:// www.biomedcentral.com/1471-2458/14/504.

23. Tiwari R, Ausman LM, Agho KE. Determinants of stunting and severe stunting among under-fives: evidence from the 2011 Nepal demographic and health survey. BMC Pediatr. 2014;14:239 PubMed CentralPubMed.

24. Monteiro CA, et al. Narrowing socioeconomic inequality in child stunting: the Brazilian experience, 1974-2007. Bull World Health Organ. 2010;88(4):305-11.

25. Willey BA, et al. Socio-economic predictors of stunting in preschool children - a population-based study from Johannesburg and Soweto. S Afr Med J. 2009; 99(6):450-6.

26. Yasmin G, Kustiyah L, Dwiriani CM. Risk factors of stunting among schoolaged children from eight provinces in Indonesia. Pak J Nutr. 2014;13(10): 557-66 Available at: http://www.scopus.com/inward/record.url?eid=2-s2. 084910054975\&partnerlD=tZOtx3y1.

27. Milman A, et al. Community and International Nutrition Differential Improvement among Countries in Child Stunting Is Associated with LongTerm Development and Specific Interventions 1. J Nutr. 2005;135:1415-22.

28. Smith LC, Ruel M, Ndiaye A. "Why is child malnutrition lower in urban than rural areas? Evidence from 36 developing countries", discussion paper 176, food consumption and nutrition division. Washington, D.C.: IFPRI; 2004.

29. Kravdal $\varnothing$, Kodzi I. Children's stunting in sub-Saharan Africa: is there an externality effect of high fertility? Demogr Res. 2011;25:565-94.

30. Ikeda N, Irie Y, Shibuya K. Determinants of reduced child stunting in Cambodia: analysis of pooled data from three demographic and health surveys. Bull World Health Organ. 2013;91:341-9 Available at: http://www. pubmedcentral.nih.gov/articlerender.fcgi?artid=3646343\&tool= pmcentrez\&rendertype=abstract.

Ready to submit your research? Choose BMC and benefit from:

- fast, convenient online submission

- thorough peer review by experienced researchers in your field

- rapid publication on acceptance

- support for research data, including large and complex data types

- gold Open Access which fosters wider collaboration and increased citations

- maximum visibility for your research: over $100 \mathrm{M}$ website views per year

At BMC, research is always in progress.

Learn more biomedcentral.com/submissions 